\title{
TRANSLOCAÇÃO DE Lactobacillus acidophilus EM RATOS ALIMENTADOS COM DIETA RICA EM COLESTEROL E ÁCIDO CÓLICO SUPLEMENTADA COM PROBIÓTICO ${ }^{1}$
}

\author{
Dayse F. M. COELHO DE SOUZA ${ }^{2, *}$, Célia L.L.F. FERREIRA², André Viana COELHO DE SOUZA \\ Neuza M. BRUNORO COSTA, Lorena M. YBARRA², Eveline M. C. AZEVEDO²
}

\section{RESUMO}

Lactobacillus acidophilus é um microrganismo bastante estudado e componente comum de probióticos. No entanto, ainda há pouca informação sobre a translocação deste microrganismo para órgãos do corpo. O presente trabalho visou investigar a taxa de translocação de Lactobacillus acidophilus em ratos que receberam uma dieta rica em colesterol, suplementada com um concentrado de células de $L$. acidophilus NCFM, visto que, o consumo deste, tem sido indicado como adjunto dietético para indivíduos hipercolesterolêmicos. Foram utilizados 130 ratos machos Wistar, com peso médio inicial de 250 $\pm 32 \mathrm{~g}$, distribuídos em 4 grupos experimentais, sendo: Padrão, com 40 animais e Controle, LDR (Leite Desnatado Reconstituído) e P (Probiótico) com 30 animais cada. O grupo Padrão recebeu a dieta AIN93G durante todo o período experimental (42dias). Os demais grupos receberam a mesma dieta acrescida de $1 \%$ de colesterol e $0,1 \%$ de ácido cólico. Durante 14 dias (do 1a ao $14^{\circ}$ dia), o grupo LDR recebeu 0,1mL/dia/animal de leite desnatado reconstituído a $10 \%$ de sólidos não gordurosos e o grupo $\mathrm{P}$, recebeu $0,1 \mathrm{~mL} / \mathrm{dia} /$ animal de probiótico contendo $10^{10} \mathrm{UFC} / \mathrm{mL}$ de Lactobacillus acidophilus NCFM. A taxa de translocação foi monitorada no $14^{\circ}, 28^{\circ}$ e $42^{\circ}$ dias de experimentação (tempo 0,14 e 28 dias após o término do consumo do probiótico, respectivamente) no baço, coração, fígado e rins. Nos órgãos dos animais dos grupos Padrão, Controle e LDR não foi observado crescimento de microrganismos nos tempos avaliados. Verificou-se translocação para o baço, coração, fígado e rins dos animais do grupo que recebeu probiótico (grupo P). O número de células de Lactobacillus encontrado nos órgãos foram, em UFC/órgão: baço $\left(8,6 \times 10^{2}\right)$; fígado $\left(4,8 \times 10^{2}\right)$; coração $\left(4,7 \times 10^{2}\right)$ e rins $\left(1,3 \times 10^{2}\right)$. Constatou-se diferença significativa $(\mathrm{p}<0,05)$ na contagem de células encontradas no baço, em comparação aos demais órgãos analisados. Entre o fígado e o coração, não foi observada diferença significativa $(p>0,05)$, mas ambos diferiram estatisticamente dos rins $(p<0,05)$. Observou-se uma eliminação constante das células translocadas após o término do consumo do probiótico, de acordo com os diferentes órgãos. O baço apresentou o maior número de células translocadas (860 UFC/órgão), no entanto, foi o órgão que as eliminou mais rapidamente. Ao final do período analisado, $69,8 \%$ das células presentes no baço, haviam sido eliminadas.

Palavras-chave: $L$. acidophilus; translocação; hipercolesterolêmico.

\section{SUMMARY}

Lactobacillus acidophilus TRANSLOCATION IN RATS FED CHOLESTEROL RICH DIET. Lactobacillus acidophilus NCFM is a strain present in several probiotic products. Despite its wide use, there is little information on its translocation to the host's organs. This work was devised to verify the Lactobacillus spp. translocation in rats feeding cholesterol rich diet because this product has been indicated as dietary adjunct for individuals hipercholesterolemic. One hundred and thirty weaned Wistar rats, divided in 4 groups and caged individually were used. The experimental groups were: Standard; Control; LDR and P. The Standard group received the AIN-93G diet during the whole experimental period (42 days). The other groups received the AIN-93G diet added of $1 \%$ of cholesterol and $0,1 \%$ of cholic acid. During 14 days, the LDR group received the supplement of $0,1 \mathrm{~mL} /$ day/animal of reconstituted skimmed milk at $10 \%$ of non fat solids and, the group $\mathrm{P}$ received $0,1 \mathrm{~mL} /$ day/animal of a probiotic in the form of a concentrate of cells contends $10^{10} \mathrm{UFC} / \mathrm{mL}$ of Lactobacillus acidophilus NCFM. Translocation was observed in spleen, heart, liver and kidneys of group P, but not in the others. The average translocation were UFC/órgão: spleen $\left(8,6 \times 10^{2}\right)$; liver $\left(4,8 \times 10^{2}\right)$; heart $\left(4,7 \times 10^{2}\right)$ and kidney $\left(1,3 \times 10^{2}\right)$. The translocated cell numbers, beside being low, were constantly eliminated during the evaluation period. Since the implication of microbial translocation in the host is not known, the translocation capacity and the rats of clearing are suggested to be important parameters for the selection of strains to be used as probiotics.

Keywords: L. acidophilus; translocation; hipercholesterolemic.

\section{1 - INTRODUÇÂO}

O termo translocação foi citado primeiramente em 1966, por WOLOCHOW, HILDEBRANT \& LAMANNA [10] para descrever a passagem de bactérias viáveis provenientes do trato-gastrintestinal para sítios extra-intestinais ou tecidos.

Segundo BERG [1] verifica-se translocação bacteriana quando; i) a população de certas bactérias in-

\footnotetext{
1. Recebido para publicação em 06/05/2002. Aceito para publicação em 20/08/2004 (000893).

2. Departamento de Tecnologia de Alimentos - Universidade Federal de Viçosa, Minas Gerais, Av. PH Rolfs, s/n, Viçosa, MG, CEP 36570-000, Brasil.E-mail: dayse.fm@bol.com.br

3. Departamento de Zootecnia - Universidade Federal de Viçosa.

4. Departamento de Nutrição e Saúde - Universidade Federal de Viçosa. * A quem a correspondência deve ser enviada.
}

testinais alcança níveis elevados; ii) quando o sistema imunológico se encontra de alguma maneira comprometido, e iii) quando a mucosa intestinal, que funciona como uma barreira, está fisicamente alterada. Além destes, fatores ambientais, como a dieta e o stress podem alterar o delicado balanço ecológico no trato-gastrintestinal promovendo também a translocação.

Translocação bacteriana da microbiota nativa, que normalmente coloniza o trato-gastrintestinal em níveis elevados, pode ocorrer em taxa reduzida e de forma "espontânea" através da mucosa de animais saudáveis [2].

De acordo com BERG [3], na presença de uma barreira mucosa intacta, a migração dos microrganismos através da parede intestinal ocorre por pinocitose (processo de ingestão de quantidades muito pequenas de 
líquido extracelular e de substâncias nele dissolvidas, sob a forma de pequenas vesículas).

No entanto, translocação bacteriana envolve interações complexas entre os mecanismos de defesa e a capacidade para transpor a barreira intestinal e sobreviver em outro ambiente, sendo necessárias mais pesquisas para elucidar os mecanismos envolvidos na passagem de microrganismos do trato-gastrintestinal para outros sítios, no hospedeiro saudável ou debilitado [2].

BERG [2] relata que a translocação de L. acidophilus do trato-gastrintestinal para outros órgãos e, ou tecidos não causa doença severa, porém, é necessário o conhecimento dos mecanismos de ação envolvidos na translocação de bactérias utilizadas como probióticos, para uma definição de seu consumo por pessoas com algum tipo de debilitação.

Objetivou-se nesta experimentação avaliar a capacidade de translocação de Lactobacillus acidophilus para o baço, coração, fígado e rins em ratos que receberam dieta rica em colesterol suplementada com Lactobacillus acidophilus NCFM por 14 dias, em uma concentração normalmente presente nos produtos probióticos. Determinou-se também, a taxa de eliminação das células viáveis translocadas dos órgãos após o final da administração do microrganismo.

\section{2 - MATERIAL E MÉTODOS}

\section{1 - Origem e manutenção da cultura}

A cultura de Lactobacillus acidophilus NCFM, de origem humana, foi obtida no Banco de Culturas do Laboratório de Culturas Láticas do Departamento de Tecnologia de Alimentos da Universidade Federal de Viçosa.

Para a confirmação de sua identidade, a cultura foi submetida à coloração de Gram, e aos testes da catalase e da fermentação dos principais açúcares.

\section{2 - Obtenção do concentrado de células de $L$. acidophilus NCFM}

A cultura de L. acidophillus NCFM foi ativada em caldo MRS. Após crescimento, seguiu-se centrifugação a 2000 x g por 20 minutos e ressuspensão em LDR 10\% de sólidos não gordurosos. O concentrado celular, que constitui-se de $10^{10} \mathrm{UFC} / \mathrm{mL}$, foi preparado a cada dois dias e mantido sob refrigeração até o momento da administração aos animais.

\section{3 - Preparo das dietas}

As dietas foram preparadas de acordo com a dieta padrão para roedores, segundo REEVES, FORREST \& FAHEY [8] modificada pela substituição de 3,5\% do óleo de soja, por gordura hidrogenada e adição de $1 \%$ de colesterol e $0,1 \%$ de ácido cólico. A composição das dietas experimentais (Padrão, Controle, LDR e P) está indicada na Tabela 1.
TABELA 1. Composição das dietas experimentais (g/100g de dieta).

\begin{tabular}{lcccc}
\hline \multirow{2}{*}{ Ingredientes } & \multicolumn{4}{c}{ Grupos } \\
\cline { 2 - 5 } & Padrão & Controle & LDR & P \\
\hline Caseína & 20,0 & 20,0 & 20,0 & 20,0 \\
Óleo de soja & 3,5 & 3,5 & 3,50 & 3,5 \\
Gordura hidrogenada & 3,5 & 3,5 & 3,5 & 3,5 \\
Colesterol cristalino & - & 1,0 & 1,0 & 1,0 \\
Ácido cólico & - & 0,1 & 0,1 & 0,1 \\
Fibras (celulose microfina) & 5,0 & 5,0 & 5,0 & 5,0 \\
Bitartarato de colina & 0,25 & 0,25 & 0,25 & 0,25 \\
Mistura de minerais & 3,5 & 3,5 & 3,5 & 3,5 \\
Mistura de vitaminas & 1,0 & 1,0 & 1,0 & 1,0 \\
L-cistina & 0,3 & 0,3 & 0,3 & 0,3 \\
Amido milho & 39,75 & 38,65 & 38,65 & 38,65 \\
\hline LDR 10\% & - & - & $0,1^{*}$ & - \\
Probiótico & - & - & - & $0,1^{*}$ \\
\hline
\end{tabular}

Fonte: Adaptado de REEVES, FORREST \& FAHEY [8]

Padrão $=$ AIN-93G

Controle $=$ dieta Padrão + colesterol +ácido cólico

$\mathrm{LDR}=$ dieta Controle $+\mathrm{LDR} 10 \%$

$*$ ml/dia/animal

\section{4 - Ensaio biológico}

Utilizaram-se 130 ratos machos da linhagem Wistar, com peso médio inicial de $250 \pm 32 \mathrm{~g}$, mantidos em gaiolas individuais em ambiente com temperatura controlada $\left(26 \pm 2^{\circ} \mathrm{C}\right)$ e ciclo claro-escuro de 12 horas. Os animais foram distribuídos em quatro grupos experimentais (Padrão, Controle, LDR e P). O grupo Padrão recebeu dieta padrão AIN-93G durante todo o período experimental (42 dias) e os demais grupos (Controle, LDR e P) receberam dieta Padrão acrescida de $1 \%$ de colesterol cristalino e $0,1 \%$ de ácido cólico. Durante 14 dias, o grupo LDR recebeu suplementação de $0,1 \mathrm{~mL} /$ dia de LDR 10\% (leite desnatado reconstituído a 10\% de sólidos não gordurosos) e o grupo $\mathrm{P}$, recebeu $0,1 \mathrm{~mL} /$ dia de probiótico, na forma de um concentrado de células, contendo $10^{10} \mathrm{UFC} / \mathrm{mL}$ de $L$. acidophilus NCFM viáveis.

No $1^{\circ}$ dia de experimentação, 10 animais do grupo Padrão foram sacrificados para o monitoramento do número de microrganismos presentes no baço, coração, fígado e rins. Seguiu-se então, a administração do probiótico e LDR aos respectivos grupos, por 14 dias. Ao final deste período ( $\left.14^{\circ} \mathrm{dia}\right)$, o qual constitui-se o tempo 0 de avaliação dos níveis de translocação, 40 ratos (10 de cada grupo) foram sacrificados por asfixia em gás $\mathrm{CO}_{2}$ seguida da incisão das cavidades torácica e abdominal para retirada dos órgãos, que foram avaliados quanto à presença de L. acidophilus. O mesmo procedimento foi repetido no $28^{\circ}$ e $42^{\circ}$ dia, ou seja, nos tempos 14 e 28 dias após o término da administração do probiótico, respectivamente. As dietas e água destilada foram oferecidas ad libitum por 42 dias.

Os órgãos foram retirados sob condições assépticas, lavados em solução salina 0,9\% estéril, acondicionados individualmente em sacos plásticos estéreis (sa- 
cos amostradores Whirl-Pak), pesados e armazenados $\mathrm{a}-80^{\circ} \mathrm{C}$ (Bio-Freezer, Forma Scientific).

Para contagem de microrganismos, cada órgão foi macerado dentro da própria embalagem e submetido à diluição de $1 / 10$ ou 1/100, conforme o órgão, com solução tampão fosfato $[6,7]$.

Seguiu-se plaqueamento em profundidade $\left(10^{\circ}, 10^{-1}\right.$, $10^{-2}, 10^{-3}$ ) em ágar MRS e incubação a $37^{\circ} \mathrm{C}$ por 48 horas. A contagem, obtida em UFC/g, foi multiplicada pelo peso de cada órgão, resultando assim, no número total de microrganismos translocados no órgão (UFC/órgão).

Após contagem, as colônias foram submetidas à coloração de Gram e ao teste da catalase para a avaliação dos microrganismos recuperados dos órgãos analisados.

\section{5 - Análise estatística}

O teste de Tukey foi utilizado para comparar as médias de contagem de microrganismos entre os órgãos no tempo 0 . Procedeu-se a análise de regressão para avaliar o efeito do tempo de eliminação sobre a contagem de microrganismos em cada órgão. O modelo de regressão testado foi descrito pela equação abaixo:

$\hat{\mathrm{Y}}=\beta_{0}+\beta_{1} \mathrm{X}$, onde

$\hat{\mathrm{Y}}=$ UFC/órgão

$\mathrm{X}=$ tempo (dias após administração do probiótico)

$\beta_{0}$ e $\beta_{1}=$ parâmetros do modelo

Para a avaliação deste modelo de regressão foram realizados os teste $\mathrm{F}$ da regressão, o teste $\mathrm{t}$ para os parâmetros e o teste $\mathrm{F}$ da falta de ajustamento do modelo. $\mathrm{O} \mathrm{R}^{2}$ foi calculado com base nas médias.

As análises estatísticas foram realizadas no Sistema SAS [9].

\section{3 - RESULTADOS E DISCUSSÃO}

\section{1 - Identificação dos microrganismos transloca- dos}

Os microrganismos translocados apresentaram características básicas de lactobacilos, ou seja gram-positivos, catalase-negativos, com morfologia e perfil de fermentação característicos de L. acidophilus, de acordo com KLANDLER \& WEISS [4] sendo positivo para maltose, glicose, galactose e lactose e negativo para sorbitol, rafinose e manitol.

\section{2 - Contagem de Lactobacillus no baço, coração, figado e rins dos animais experimentais}

As Tabelas 2, 3, 4 e 5 mostram as médias \pm desvio padrão, em UFC/órgão, da contagem de lactobacilos no baço, fígado, coração e rins de acordo com os grupos experimentais e tempos monitorados.
TABELA 2. Contagem (média \pm desvio padrão) em UFC/órgão, de lactobacilos no baço dos animais, de acordo com os grupos experimentais e tempos monitorados $(0,14 \mathrm{e}$ 28 dias após o término do consumo do probiótico).

\begin{tabular}{lcccc}
\hline \multirow{2}{*}{ Tempo } & \multicolumn{4}{c}{ Grupos } \\
\cline { 2 - 5 } 0 & Padrão & Controle & LDR & $\mathrm{P}$ \\
\cline { 2 - 5 } 14 & 0,00 & 0,00 & 0,00 & $8,5 \times 10^{2} \pm 19,32$ \\
28 & 0,00 & 0,00 & 0,00 & $5,7 \times 10^{2} \pm 19,13$ \\
& 0,00 & 0,00 & 0,00 & $2,5 \times 10^{2} \pm 12,31$ \\
\hline
\end{tabular}

Padrão = AIN-93G [8]

Controle $=$ dieta Padrão + colesterol +ácido cólico $\mathrm{LDR}=$ dieta Controle + LDR $10 \%$

$\mathrm{P}=$ dieta Controle + probiótico

TABELA 3. Contagem (média \pm desvio padrão) em UFC/órgão, de lactobacilos no fígado dos animais, de acordo com os grupos experimentais e tempos monitorados $(0,14 \mathrm{e}$ 28 dias após o término do consumo do probiótico).

\begin{tabular}{lcccc}
\hline \multirow{2}{*}{ Tempo } & \multicolumn{3}{c}{ Grupos } \\
\cline { 2 - 5 } 0 & Padrão & Controle & LDR & $\mathrm{P}$ \\
\cline { 2 - 5 } 14 & 0,00 & 0,00 & 0,00 & $5,0 \times 10^{2} \pm 130,94$ \\
28 & 0,00 & 0,00 & 0,00 & $3,0 \times 10^{2} \pm 87,90$ \\
& 0,00 & 0,00 & 0,00 & $2,3 \times 10^{2} \pm 114,96$ \\
\hline
\end{tabular}

Padrão $=$ AIN-93G [8]
Controle = dieta Padrão + colesterol +ácido cólico

Controle $=$ dieta Padrao + colester
LDR = dieta Controle + LDR $10 \%$

$\mathrm{P}=$ dieta Controle + probiótico

TABELA 4. Contagem (média \pm desvio padrão) em UFC/ órgão, de lactobacilos no coração dos animais, de acordo com os grupos experimentais e tempos monitorados (0, 14 e 28 dias após o término do consumo do probiótico).

\begin{tabular}{lcccc}
\hline \multirow{2}{*}{ Tempo } & \multicolumn{3}{c}{ Grupos } \\
\cline { 2 - 5 } 0 & Padrão & Controle & LDR & P \\
\cline { 2 - 5 } 14 & 0,00 & 0,00 & 0,00 & $4,8 \times 10^{2} \pm 18,80$ \\
28 & 0,00 & 0,00 & 0,00 & $3,0 \times 10^{2} \pm 20,45$ \\
& 0,00 & 0,00 & 0,00 & $1,9 \times 10^{2} \pm 13,68$ \\
\hline
\end{tabular}

Padrão $=$ AIN-93G [8]

Controle = dieta Padrão + colesterol +ácido cólico $\mathrm{LDR}=$ dieta Controle $+\mathrm{LDR} 10 \%$

TABELA 5. Contagem (média \pm desvio padrão) em UFC/órgão, de lactobacilos nos rins dos animais, de acordo com os grupos experimentais e tempos monitorados $(0,14 \mathrm{e}$ 28 dias após o término do consumo do probiótico).

\begin{tabular}{lcccc}
\hline \multirow{2}{*}{ Tempo } & \multicolumn{3}{c}{ Grupos } \\
\cline { 2 - 5 } 0 & Padrão & Controle & LDR & $\mathrm{P}$ \\
\cline { 2 - 5 } 14 & 0,00 & 0,00 & 0,00 & $1,3 \times 10^{2} \pm 83,09$ \\
28 & 0,00 & 0,00 & 0,00 & $1,0 \times 10^{2} \pm 25,25$ \\
& 0,00 & 0,00 & 0,00 & $8,2 \times 10^{1} \pm 38,36$ \\
\hline
\end{tabular}

Padrão $=$ AIN-93G [8]

Controle $=$ dieta Padrão + colesterol +ácido cólico

$\mathrm{LDR}=$ dieta Controle $+\mathrm{LDR} 10 \%$

$\mathrm{P}=$ dieta Controle + probiótico

Constatou-se a passagem de microrganismos viáveis do trato-gastrintestinal para todos os órgãos avaliados (coração, rins fígado e baço), quando os animais receberam dieta rica em colesterol suplementada com 
$10^{10} \mathrm{UFC} / \mathrm{mL}$ de L. acidophilus NCFM viáveis, durante 14 dias (grupo P).

Nos órgãos dos animais dos grupos Padrão, Controle e LDR não foi observada a presença de Lactobacillus em nenhum dos tempos analisados.

Imediatamente, após o término da administração do probiótico (tempo 0), de acordo com o modelo de regressão ajustado, o número de células viáveis encontradas nos órgãos foram: baço (8,6 x 10 ${ }^{2}$ UFC/órgão);

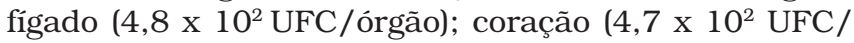
órgão) e rins ( $1,3 \times 10^{2} \mathrm{UFC} /$ órgão). A contagem observada no baço foi significativamente maior $(\mathrm{p}<0,05)$ do que a encontrada nos outros órgãos avaliados. Entre o fígado e o coração não foi observada diferença significativa ( $\mathrm{p}>0,05)$, quanto ao número de células translocadas. Nos rins, contatou-se o menor índice de translocação, quando comparado aos demais órgãos analisados.

Embora, os números observados nesse estudo, sejam considerados baixos, corroboram informações de BERG [2] onde o autor se refere ao L. acidophilus como um microrganismo que possui pouca capacidade de translocar, mesmo quando administrado em concentrações elevadas.

Ainda, segundo BERG [2], fatores ambientais, como a dieta, podem alterar o delicado balanço ecológico no trato-gastrintestinal e provocar a passagem de microrganismos para outros órgãos e, ou tecidos.

Sugere-se que a dieta rica em colesterol e ácido cólico administrada aos animais, nessa experimentação, de algum modo, pode ter causado alteração na mucosa intestinal dos ratos, com aumento de sua permeabilidade, permitindo assim, a translocação, como foi verificado por MOREHOUSE et al. [5], que constataram a passagem de bactérias anaeróbias estritas e facultativas do trato-intestinal para órgãos, como o fígado e baço, em ratos que tinham perdido a integridade da mucosa pela administração de ácido ricinóleico.

\section{3 - Desaparecimento de células viáveis de Lactobacillus dos órgãos dos animais que recebe- ram probiótico}

Após o período de administração do probiótico, verificou-se que os microrganismos foram eliminados em diferentes taxas de acordo com os órgãos analisados (Figura 1).

A eliminação das bactérias nos diferentes órgãos seguiu o modelo de regressão descrito pela equação abaixo:

$\hat{\mathrm{Y}}=\beta_{0}+\beta_{1} \mathrm{X}$

$\hat{\mathrm{Y}}=\mathrm{UFC} /$ órgão

$\mathrm{X}=$ tempo (dias após administração do probiótico)

$\beta_{0}$ e $\beta_{1}=$ parâmetros do modelo

O tempo de eliminação completa dos microrganismos translocados, para cada órgão, foi calculado a partir dos modelos de regressão ajustados (Tabela 6).

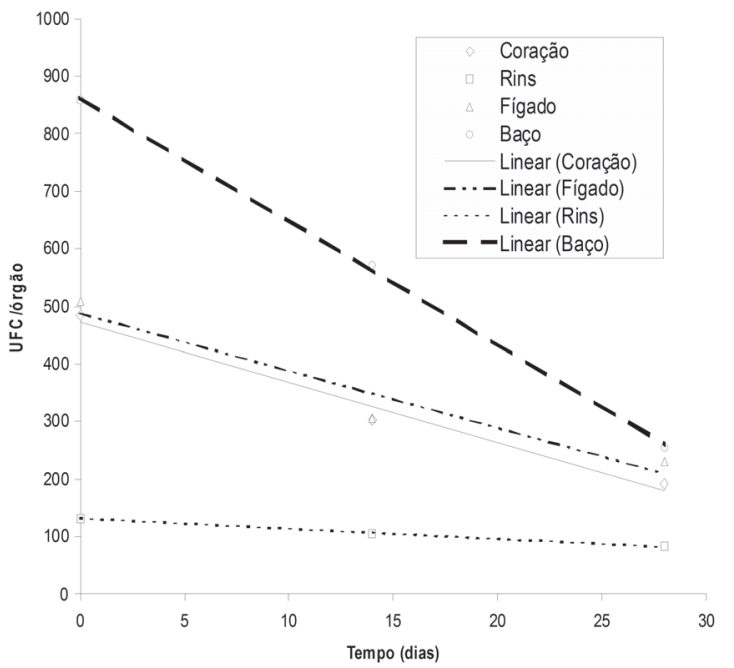

FIGURA 1. Contagem de Lactobacillus nos diferentes órgãos, durante os 28 dias após o final da administração do probiótico.

TABELA 6. Modelos de regressão ajustados para os diferentes órgãos.

\begin{tabular}{lcc}
\hline Órgão & \multicolumn{1}{c}{ Modelo ajustado } & $\mathrm{R}^{2}$ \\
\hline Baço & $\mathrm{y}=863,9500-21,5542 \mathrm{x}$ & 0,99 \\
Coração & $\mathrm{y}=472,5416-10,4196 \mathrm{x}$ & 0,98 \\
Fígado & $\mathrm{y}=487,8023-9,9409 \mathrm{x}$ & 0,93 \\
Rins & $\mathrm{y}=131,3616-1,7742 \mathrm{x}$ & 0,99 \\
\hline
\end{tabular}

Em todos os órgãos, a eliminação completa não foi alcançada dentro do período de tempo estudado. Vinte e oito dias após o término do consumo do probiótico, os números de células presentes nos órgãos (em UFC/ órgão), estimados pelos modelos de regressão ajustados, foram: $2,6 \times 10^{2}$, para o baço; $2,0 \times 10^{2}$, para o fígado; $1,8 \times 10^{2}$, para o coração e $8,1 \times 10^{1}$, para os rins. Permanecendo a tendência verificada neste período, a eliminação completa aconteceria, no baço, em 40 dias, no coração, em 45, no fígado, em 49 e nos rins, em 74 dias. O baço, apresentou o maior número de células translocadas (860UFC/órgão), no entanto, foi o órgão que as eliminou mais rapidamente. Ao final do período analisado, 69,8\% das células presentes no baço, haviam sido eliminadas.

No baço, o número elevado de histiócitos (células fagocíticas pertencentes à classe dos leucócitos que desempenham papel essencial na proteção do organismo contra a invasão de bactérias) poderia justificar o menor tempo de eliminação dos microrganismos translocados para este órgão, apesar do número inicial de células ter sido maior, quando comparado com o fígado, coração e rins.

\section{4 - CONCLUSÕES}

- Produtos probióticos têm sido indicados como adjunto dietético na promoção da saúde e na pre- 
venção de doenças. É importante, pois, que a taxa de translocação dos microrganismos utilizados nestes produtos e o tempo para sua completa eliminação sejam mais um parâmetro no processo de seleção de estirpes, candidatas a compor um probiótico, uma vez que se desconhece, atualmente, as implicações deste processo.

\section{5 - REFERÊNCIAS BIBLIOGRÁFICAS}

[1] BERG, R.D. Mechanisms confining indigenous bacteria to the gastrointestinal tract. Am. J. Clin.Nutr., v. 33, p. 2472-2484, 1980.

[2] BERG, R.D. Translocation and the indigenous gut flora. In: FULLER, R. (Ed.) Probiotics: the scientific basis. London: Champman e Hall, 1992; p. 55-85.

[3] BERG, R.D. Bacterial translocation from the gastrointestinal tract. Trends Microbiol. v. 3, p. 149-54, 1995.

[4] KANDLER, O.; WEISS, N. Regular, nonsporing grampositive rods. In: BERGEY, D.H. Bergey's manual of sistematic bacteriology. Baltimore: Willians e Wilkins, 1993; 9 ed., v. 2, p. 1208-1223.

[5] MOREHOUSE, J.; SPECIAN, R.; STEWART, J.; BERG, R.D. Promotion of translocation of indigenous bacteria of mice from the GI tract by oral ricinoleic acid. Gastroenterology, v. 91, p. 637-82, 1986.
[6] NADER DE MACIAS, M.E.; ROMERO, N.C.; APELLA, M.C.; GONZALEZ, S.N.; OLIVER, G. Prevention of infections produced by Escherichia coli by feeding milk fermented with lactobacilli. J. Food Prot. v. 56, p. 401-405, 1993.

[7] NADER DE MACIAS, M.E.; APELLA, M.C.; ROMERO, N.C.; GONZALEZ, S.N.; OLIVER, G. Inhibition of Shigella sonnei by Lactobacillus casei and Lactobacillus acidophilus. J. Applied Bacteriology, v. 73, p. 407$411,1992$.

[8] REEVES, P.G.; FORREST, H.N.; FAHEY, G.C.Jr. AIN93 Purified diets for laboratory rodents: final report of the American Institute of Nutrition Ad Hoc Writing Committee on the Reformulation of the AIN-76 A Rodent Diet, J. Nutr. v. 123, p. 1939-1951, 1993.

[9] SAS Institute, 1982. SAS User's Guide: Statistics. 1982 Edition. SAS Institute Inc. Cary, NC.

[10] WOLOCHOW, G; HILDEBRANT, G.J.; LAMANNA, C. Translocation of microrganism across the intestinal wallof the rats: effect of microbial size and concentrations. Journal of Infectious Diseases, v. 116, p. 523-8, 1996.

\section{6 - AGRADECIMENTOS}

Os autores agradecem o apoio financeiro da FAPEMIG e CAPES. 